\title{
INDIGENOUS PEOPLE KAMPUNG KUTA KABUPATEN CIAMIS: KAJIAN ETNOBOTANI PEMANFAATAN KELAPA (Cocos nucifera L.)
}

\author{
Fira Regina Ryandita ${ }^{1 *}$, Diana Hernawati ${ }^{2)}$, Rinaldi Rizal Putra ${ }^{3)}$ \\ 1,2,3) Jurusan Pendidikan Biologi, FKIP, Universitas Siliwangi \\ *email: firareginary@gmail.com
}

\section{Diterima 12 September 2020 disetujui 18 Okober 2020 diterbitkan 11 November 2020}

\begin{abstract}
Cocos nucifera L. is a plant species from the Areacaceae family which is widely used by the indigenous people of Kampung Kuta, Ciamis Regency. The indigenous people of Kampung Kuta are still upholding the traditions of life to maintain the balance of nature and the local socio-cultural order, but it is very unfortunate that the use of Cocos nucifera L. by the indigenous people of Kampung Kuta has not been documented in writing, so they are afraid of community traditions and local wisdom values. existing ones can be lost. For this reason, this study aims to describe the ethnobotany of the use of Cocos nucifera by the indigenous people of Kampung Kuta. This research was conducted in Kuta Traditional Village in June 2020, this research is a qualitative descriptive study using the phenomenological method, data collection using purposive sampling technique with semistructured interviews. The informants in this study amounted to 20 people, namely 13 women and 7 men with an informant age range of 30-67 years. The results showed that there were 19 ways to use coconut which were classified into 5 categories of use, namely as a food source, building materials, used as medicinal plants, handicrafts and traditional ceremonies.
\end{abstract}

Keywords: Cocos nucifera L, Ethnobotany, Indegenous people of Kampung Kuta.

\section{PENDAHULUAN}

Beragam jenis tumbuhan merupakan sumberdaya yang telah digunakan manusia sudah sejak lama, sejak zaman dahulu masyarakat memiliki hubungan yang erat dengan lingkungan terutama dalam hal pemanfaatan tumbuhan. Interaksi manusia dengan tumbuhan sangat penting, sehingga minat mempelajari tumbuhan telah timbul sepanjang sejarah manusia di bumi. Adapun ilmu yang mempelajari hubungan manusia dengan tumbuhan disebut dengan etnobotani. Etnobotani didefinisikan sebagai suatu ilmu yang mempelajari pengetahuan tentang pemanfaatan, pengelolaan tumbuhan secara tradisional atau lokal oleh suatu etnis, suku atau masyarakat (Batori, 2015; Mesfin, Tekle, \& Tesfay, 2013). Hal ini yang menyebabkan pengetahuan modern manusia tentang berbagai pemanfaatan tumbuhan tidak dapat dilepaskan dari sumbangan ilmu pengetahuan yang tersebar di berbagai masyarakat tradisional yang memiliki hubungan erat dengan berbagai jenis tumbuhan. Salah satu jenis tumbuhan yang banyak sekali dimanfaatkan oleh masyarakat salah satunya spesies tumbuhan dari familia Arecacae yaitu kelapa.

Kelapa merupakan tumbuhan serba guna dikarenakan setiap bagian organ dapat dimanfaatkan oleh manusia, sehingga kerap kali dijuluki sebagai "Tree of Life" atau pohon kehidupan (Kriswiyanti,2013). Kelapa merupakan komoditas strategis yang memiliki peran sosial, budaya dan ekonomi dalam kehidupan masyarakat Indonesia (Pratiwi dan Pande, 2013). Masyarakat tradisional Indonesia yang memiliki hubungan erat dalam pemanfaatan Kelapa (Cocos nucifera L.) salah satunya yaitu indigeonous people yang dimiliki masyarakat adat Kampung Kuta.

Masyarakat adat Kampung Kuta memanfaatkan kelapa dalam kehidupan sehari-hari seperti untuk kebutuhan pangan, bahan bangunan, dimanfaatkan sebagai tanaman obat, kerajinan tangan dan ritual upacara adat. Sejalan dengan hal tersebut, ditemukan adanya suatu masalah yaitu tidak adanya dokumentasi tertulis mengenai pemanfaatan kelapa (Cocos nucifera L.) 
oleh masyarakat adat Kampung Kuta, sehingga dikhawatirkan berbagai nilai-nilai kearifan lokal yang terdapat dalam ragam jenis pemanfaatan tumbuhan dapat hilang apabila tidak adanya pendokumentasian secara tertulis. Berdasarkan hal tersebut, penelitian ini bertujuan untuk mendeskripsikan etnobotani pemanfaatan (Cocos nucifera L.) oleh masyarakat adat Kampung Kuta.

\section{METODE}

Penelitian ini dilakukan di Kampung Adat Kuta, Kabupaten Ciamis. Sampel dari penelitian ini adalah masyarat adat Kampung Kuta. Pengambilan sampel dilakukan dengan teknik purposive sampling menggunakan wawancara terstruktur (Mcinch \& Mcinch, 2019). Jumlah informan sebanyak 20 orang yaitu 13 orang wanita dan 7 orang pria dengan rentang usia informan 30-67 tahun.

Informasi yang disajikan dalam penelitian ini merupakan bagian dari rangkaian data yang dikumpulkan oleh penulis pada bulan Juni 2020. Jenis penelitian ini merupakan penelitian deskriptif kualitatif dengan menggunakan metode fenomenologi. Teknik analisis data dilakukan secara kualitatif, untuk kualitatif dilakukan aktivitas analisis data seperti data reduction, data display, dan verification (Creswell, 2013).

\section{HASIL DAN PEMBAHASAN}

Berdasarkan hasil penelitian mengenai etnobotani pemanfaatan Cocos nucifera $\mathrm{L}$. oleh masyarakat adat Kampung Kuta, ditemukan 5 jenis pemanfaatan kelapa, adapun masyarakat adat memanfaatkan kelapa seperti untuk sumber pangan, bahan bangunan, dimanfaatkan untuk tanaman obat, kerajinan tangan dan juga ritual upacara adat.

1. Pemanfaatan kelapa untuk pangan

Masyarakat adat Kampung Kuta memanfaatkan kelapa untuk keperluan pangan yaitu salah satunya dengan memanfaatkan bagian daging buah kelapa untuk dikonsumsi secara langsung ataupun diolah kembali untuk dijadikan santan dan urap. Pada bagian endosperma padat atau daging buah kelapa biasa digunakan masyarakat di Indonesia sebagai bahan baku santan dan olahan urap-urapan dan serundeng (Ami dan Evi Ayu, 2019)

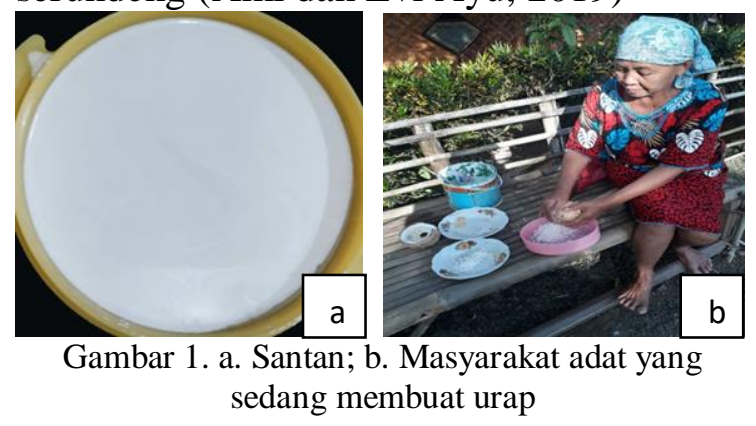

2. Pemanfaatan Kelapa Untuk Bahan Bangunan

Pohon kelapa merupakan salah satu jenis palem yang banyak dimanfaatkan untuk bahan bangunan oleh masyarakat adat Kuta. Bagian batang kelapa dimanfaatkan oleh masyarakat adat untuk dijadikan tiang penyangga rumah, pondasi atap rumah dan juga jembatan.

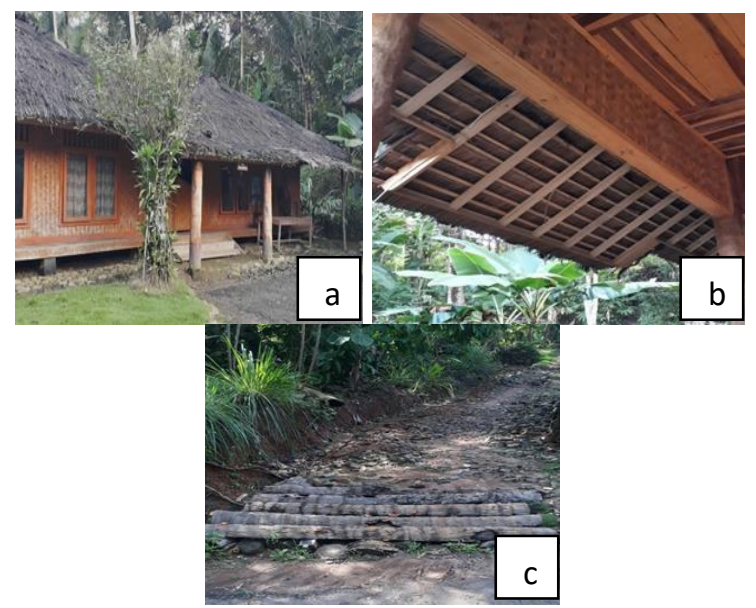

Gambar 2. a. pemanfaatan batang kelapa untuk tiang rumah; b. pemanfaatan batang kelapa untung pondasi atap rumah; c. pemanfaatan batang kelapa untuk jembatan.

Kayu kelapa dapat dijadikan salah satu pilihan bahan bangunan karena memiliki corak yang estetis, unik dan ketahanan kayu yang kuat dikarenakan 
komposisi kayu kelapa terdiri dari $66,7 \%$ holocellulose, $25,1 \%$ lignin dan $22,9 \%$ pentosans dan memiliki serat yang sangat rapat sehingga kayu kelapa termasuk kedalam jenis kayu kuat dan awet (Indrosaptono, et.al, 2014).

\section{Pemanfaatan Kelapa sebagai Tanaman} Obat

Pohon kelapa dimanfaatkan oleh masyarakat adat Kampung Kuta sebagai tanaman obat. Masyarakat adat memanfaatkan bagian air kelapa untuk mengobati sakit perut, memperlancar buang air kecil, menghilangkan dehidrasi, mengurangi rasa mual saat hamil dan dipercaya bermanfaat untuk mengurangi nyeri saat haid. Air kelapa muda mengandung vitamin c, kalsium dan magnesium, kalsium dan magnesium dapat mengurangi ketegangan otot dan vitamin $\mathrm{c}$ sendiri merupakan zat alami anti inflamasi yang membantu meringankan rasa sakit akibat kram saat menstruasi (Amiritha, 2017). Selain itu air kelapa mengandung elektrolit alami antara lain kalsium, kalium, natrium dan glukosa yang dapat digunakan untuk mengatasi dehidrasi (Hasibuan dan Simanullang, 2018).

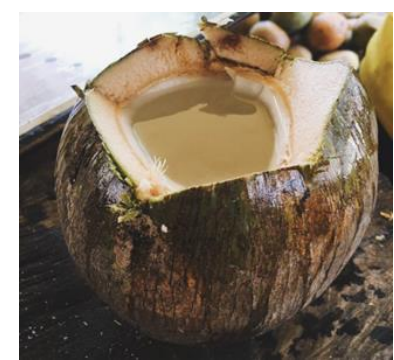

Gambar 3. Pemanfaatan air kelapa oleh masyarakat adat Kampung Kuta sebagai obat untuk mengobati beberapa penyakit.

\section{Pemanfaatan Kelapa Untuk Kerajinan Tangan}

Kelapa merupakan tumbuhan dari familia Arecaceae yang dimanfaatkan oleh masyarakat adat untuk dibuat kerajinan tangan, adapun bagian tanaman yang dimanfaatkan itu yaitu bagian buahnya pada bagian tempurung kelapa biasa dimanfaatkan oleh masyarakat untuk dibuat gelas, teko, asbak. Selain itu sebagian warga juga menggunakan tempurung kelapa untuk dibuat gayung. Pada bagian tulang daun kelapa juga biasanya dimanfaatkan untuk membuat sapu lidi, dan pada bagian daun kelapa yang kering biasanya dibuat untuk pembungkus gula aren.

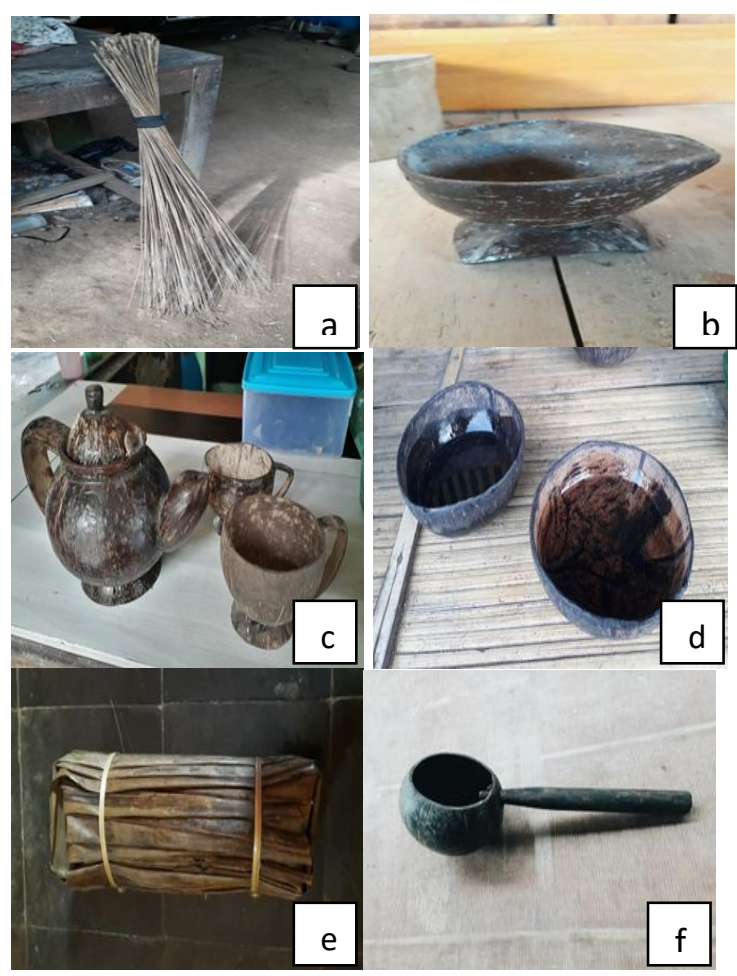

Gambar 4. a. Pemanfaatan kelapa untuk kerajinan tangan yang dimanfaatkan untuk dibuat sapu lidi; b. asbak; c. teko; d. gelas; e. pembungkus gula aren; f. gayung.

\section{Pemanfaatan Kelapa untuk Ritual Upacara Adat}

Masyarakat adat Kampung Kuta memiliki hubungan erat dengan kelapa, terutama dalam pemanfaatannya untuk keperluan ritual upacara adat. Kebiasaan ini dilakukan secara temurun di Kampung adat Kuta. Pengetahuan tradisional dapat diturunkan secara lisan dari satu generasi ke generasi lainnya melalui percobaan dan metode kesalahan (Rajakumar \& Shivanna, 2010). Adapun beberapa ritual upacara adat yang memanfaatkan pohon kelapa yaitu sebagai berikut : 


\section{Ritual Upacara Adat Nyuguh}

Upacara adat nyuguh merupakan upacara adat yang dilaksanakan setiap satu tahun sekali bertepatan pada tanggal 25 safar setiap tahunnya. Ritual upacara adat nyuguh bertujuan sebagai bentuk rasa syukur kepada Tuhan Yang Maha Esa dan leluhur yang telah memberikan kelancaran rizki dan dihindarkan dari malapetaka. Bagian pohon kelapa yang dimanfaatkan oleh masyarakat adat untuk ritual upacara adat nyuguh adalah bagian daun kelapa. Daun kelapa dimanfaatkan untuk membuat ketupat yang dimana ketika ritual nyuguh dimulai setiap masyarakat adat diwajibkan membawa ketupat, yang mana pada sore hari ketupat tersebut akan diarak bersama dengan hasil panen, makanan khas dan simbol lainnya. Ritual dilaksanakan di tepi barat sungai Cijolang yang berada di ujung timur Kampung Kuta. Setelah ritual upacara adat nyuguh selesai kemudian seluruh masyarakat melakukan kegiatan makan bersama sebagai tanda syukur dan ajang silaturahmi antar masyarakat adat.

Selain dimanfaatkan untuk pembuatan ketupat, daun kelapa juga digunakan untuk pembuatan umbul-umbul atau bendera sebagai tanda sedang dilaksanakannya suatu upacara adat atau perayaan besar lainnya.

\section{Ritual Upacara Adat Babarit}

Babarit merupakan ritual yang dilakukan oleh seluruh masyarakat adat Kampung Kuta ketika setelah terjadi fenomena bencana alam berupa gempa bumi atau terjadi kemarau panjang, ketika ritual babarit akan dilaksanakan. Biasanya aki sesepuh selaku tokoh adat di Kampung Kuta memberikan syarat kepada masyarakat adat untuk membawa sawen. Sawen merupakan kumpulan jenis-jenis tanaman yang harus dibawa oleh masyarakat adat, yang dipercaya sebagai bentuk tolak bala atau penjagaan agar tidak terkena musibah dan marabahaya.
Daun kelapa juga dimanfaatkan sebagai syarat tanaman yang harus ada dalam sawen yang nantinya diikat bersamaan dengan tanaman lain sesuai dengan syarat yang diminta oleh aki sesepuh. Setiap fenomena bencana alam yang terjadi syarat tanaman-tanaman yang dimanfaatkan untuk sawen berbeda-beda tergantung apa yang amanatkan oleh aki sesepuh. Apabila ritual sudah dilaksanakan, sawen boleh dibawa pulang kembali oleh masyarakat dan biasanya dianjurkan agar disimpan di atas setiap pintu rumah.

\section{Ritual Upacara Adat Nebus Weteng}

Nebus Weteng merupakan ritual yang biasa dilaksanakan oleh masyarakat adat. Ritual ini dilaksanakan saat janin berumur tujuh bulan dalam kandungan ibunya hal ini dimaksudkan agar proses persalinan nanti dapat berjalan dengan lancar tanpa hambatan apapun serta merupakan bentuk rasa syukur karena janin sudah mencapai usia tujuh bulan. Bagian pohon kelapa yang dimanfaatkan oleh masyarakat adat adalah bagian buah kelapa yang digunakan sebagai syarat yang harus ada dalam prosesi ritual nebus weteng. Selain buah kelapa juga terdapat buahbuahan lain, umbi-umbian serta tujuh macam bunga yang dijadikan syarat.

\section{Nyekar Ka Leuweung Gede}

Leuweung Gede merupakan hutan seluas 40 hektar yang dikeramatkan oleh masyarakat adat Kampung Kuta. Kegiatan nyekar (ziarah) ke Leuweung Gede merupakan kegiatan yang kerap kali dilakukan oleh masyarakat adat atau pun masyarakat luar. Sejumlah aturan adat diberlakukan bagi mereka yang ingin nyekar (ziarah) salah satunya seperti Leuweung gede hanya boleh dimasuki setiap hari senin dan jumat, tidak boleh meludah dan menggunakan alas kaki ketika akan masuk ke hutan. Khusus bagi kuncen atau juru kunci Leuweung Gede, mereka memanfaatkan salah satu bagian dari pohon 
kelapa yaitu bagian seludang bunga atau masyarakat adat Kampung Kuta biasa menyebutnya "mancung kalapa". Para kuncen atau juru kunci memanfaatkan seludang bunga yang sudah kering sebagai tempat untuk membakar kemenyan apabila kegiatan nyekar akan dimulai. Menurut salah satu juru kunci kemenyan akan lebih lama menyala apabila dibakar diatas mancung kalapa atau seludang bunga kelapa tersebut.

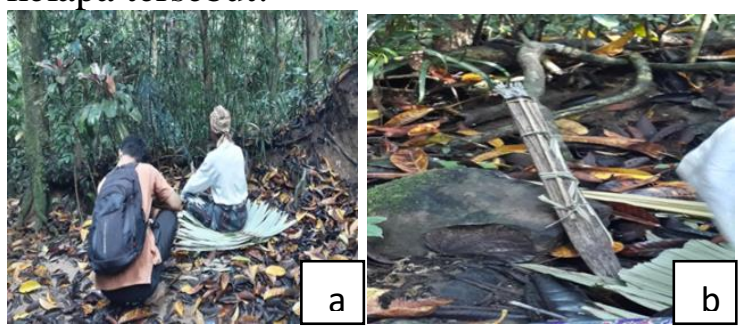

Gambar 5. a. Prosesi ritual Nyekar Ka Leuweung Gede; b. seludang bunga kelapa yang dimanfaatkan untuk tempat membakar kemenyan.

6. Kajian Fenomenologi Pemanfaatan Cocos nucifera L. Berdasarkan Nilai Kearifan Lokal Di Kampung Adat Kuta

Masyarakat adat Kampung Kuta memiliki hubungan yang erat dalam hal pemanfaatan kelapa, berdasarkan fenomena tersebut penulis mewawancarai salah satu tokoh adat yaitu $\mathrm{Ki}$ Warja, beliau merupakan tokoh adat yang dihormati atau dituakan (sesepuh) oleh masyarakat adat Kampung Kuta. Sebagaimana yang kita ketahui bahwa sebagian besar masyarakat adat Kampung Kuta bermata pencaharian petani. Menurut Ki Warja sampai saat ini masyarakat percaya bahwasannya Sang Hyang Dewi Sri atau Nyi Pohaci merupakan dewi kesuburan yang ikut andil memberikan kemakmuran dalam bidang pertanian. Dalam hal pemanfaatan kelapa oleh masyarakat adat hal memiliki keterkaitan erat dengan Sang Hyang Dewi Sri. Menurut Ki Warja beliau menceritakan bahwasannya asal mula pohon kelapa, merupakan jenis tumbuhan yang tumbuh dari dalam kuburan Sang Hyang Dewi Sri, ketika jenazah Sang Hyang Dewi Sri dibawa turun ke bumi dan dikuburkan, karena kesucian Sang Hyang Dewi Sri maka dari dalam kuburannya muncul beragam jenis tumbuhan yang sampai saat ini bermanfaat bagi umat manusia.

Adapun beberapa tumbuhan yang tumbuh dari kuburan Sang Hyang Dewi Sri menurut penuturan Ki Warja dipercaya dari bagian kepala muncul pohon kelapa. Dari bagian alat kelaminnya muncul pohon aren dan dari ibu jari Sang Hyang Dewi Sri muncul pohon pinang. Selain itu dari bagian pusar muncul tanaman padi, Ki Warja mengatakan bahwasannya disetiap anggota tubuh Sang Hyang Dewi Sri muncul beragam tanaman yang bermanfaat. Maka dari itu menurut beliau, pohon kelapa, aren dan pinang banyak tumbuh subur dan banyak dimanfaatkan oleh masyarakat adat Kampung Kuta karena masyarakat percaya bahwasannya kelapa, aren dan pinang merupakan perlambang kesuburan dan kemakmuran yang patut dimanfaatkan sebagai bentuk rasa syukur atas apa yang telah alam berikan.

Selain itu menurut $\mathrm{Ki}$ Warja banyaknya pohon kelapa yang ditemukan dan dimanfaatkan oleh masyarakat adat juga memiliki hubungan erat dengan petunjuk atau perintah dari Ki Bumi kepada masyarakat Kampung Kuta pada zaman dahulu. Adapun $\mathrm{Ki}$ Bumi merupakan seorang utusan Raja Cirebon yang ditugaskan untuk menyebarkan agama islam ke daerah selatan. Selain itu Ki Bumi juga merupakan kuncen (juru kunci) pertama sebagai peletak dasar kehidupan di Kampung Kuta, semua tingkah laku dan ucapan Ki Bumi sampai sekarang masih dijadikan pedoman oleh masyarakat adat Kampung Kuta. Pada zaman dahulu Ki Bumi memberikan perintah kepada masyarakat yang waktu itu menempati daerah Kampung Kuta untuk menanam 16 jenis pohon salah satunya yaitu pohon kelapa, aren, pinang. Selain itu ada juga beberapa jenis tanaman lain yang harus ditanam seperti ki kandel, ki tetel, jawer kotok (Coleus atropurpureus), sanggabuana, kaso bodas (Saccharum spontaneum), panglay (Zingiber 
montanum), sirih (Piper betle), oar, pacing (Cheilocostus speciosus), bambu kuning (Bambusa vulgaris var. striata), tiwu hideung (Saccharum officinarum L), jukut palias (Lophantherum gracile) dan sulangkar (Leea sambucina).

Berdasarkan dari kedua penjelasan tersebut dapat disimpulkan bahwasannya fenomena banyaknya ragam pemanfaatan kelapa oleh masyarakat adat Kampung Kuta memiliki keterkaitan dengan nilainilai kearifan lokal yang sampai saat ini masih dijaga oleh masyarakat adat Kampung Kuta. Hubungan masyarakat adat Kampung Kuta dengan kelapa (Cocos nucifera L) tidak hanya sebatas memanfaatkan apa yang alam berikan, tetapi masyarakat adat Kampung Kuta memiliki andil yang besar dalam merawat keragaman budaya sekaligus melindungi keanekaragaman hayati yang ada. Selaras dengan apa yang disampaikan oleh $\mathrm{Ki}$ Warja beliau mengatakan bahwa dengan memegang teguh budaya dan aturan adat merupakan cara masyarakat adat Kampung Kuta untuk ikut menjaga keseimbangan alam dan terpeliharanya tatanan hidup.

\section{SIMPULAN}

Berdasarkan hasil penelitian dapat disimpulkan bahwa masyarakat adat Kampung Kuta memiliki hubungan yang erat dengan ragam pemanfaatan kelapa, terdapat 19 cara pemanfaatan kelapa yang tergolong ke dalam 5 kategori pemanfaatan yaitu sebagai sumber pangan, bahan bangunan, dimanfaatkan sebagai tanaman obat, kerajinan tangan dan ritual upacara adat.

\section{DAFTAR PUSTAKA}

Ami, M. S \& Candra, E. A. (2019). Identifikasi Tumbuhan Dalam Masakan Tradisional Urap-Urap Sebagai Materi Penyusun Buku Referensi Taksonomi Tumbuhan. Edubiotik: Jurnal Pendidikan, Biologi dan Terapan, 4 (2), 83 - 92.
Batori, J. (2015). Pengelolaan Lingkungan dengan Pendekatan EtnobiologiEtnobotani. Malang: Universitas Brawijaya Press.

Creswell, J. W. (2013). Educational Research: Planning, Conducting, and Evaluating Quantitative and Qualitative Research. Journal of Chemical Information and Modeling. https://doi.org/10.1017/ CBO9781107415324.004

Hasibuan, R., Simanullang, R. J. (2018). Pengaruh Pemberian Air Kelapa Muda Terhadap Tingkat Status Hidrasi Cairan Tubuh Setelah Melakukan Aktivitas Olahraga. Jurnal Ilmiah Ilmu Keolahragaan, 2(1). $42-51$.

Indrosaptono, D., Sukawi., Indraswara, M. S. (2014). Kayu Kelapa (Glugu) Sebagai Alternatif Bahan Konstruksi Bangunan. MODUL, 14(1). $53-58$.

Kriswiyanti, E. (2013). Keanekaragaman Karakter Tanaman Kelapa (Cocos nucifera L) Yang Digunakan Sebagai Bahan Upacara Padudusan Agung. Jurnal Biologi, 1. 15 - 19.

Mcinch, A., \& Mcinch, A. (2019). The only way is ethics: methodological considerations for a working-class academic a working-class academic, 7823. https://doi.org/10.1080/ 17457823.2019.1631868

Mesfin, K., Tekle, G., \& Tesfay, T. (2013). Ethnobotanical Study of Traditional Medicinal Plants Used by Indigenous People of Gemad District, Northern Ethiopia. Journal of Medicinal Plants Studies, 1(4), $32-37$. 
Pratiwi, F.M., Sutara, P.K. (2013).

Etnobotani Kelapa (Cocos

nucifera L.) Di Wilayah Denpasar

Dan Badung. Jurnal Simbiosis, 1: 102-111

Rajakumar, N., \& Shivanna, M. B. (2010).

Traditional herbal medicinal

knowledge in Sagar taluk of

Shimoga district, Karnataka, India.

Indian Journal of Natural Products

and Resources, 1(1), 102-108. 